\title{
Guar gum-grafted poly(acrylonitrile)- templated silica xerogel: nanoengineered material for lead ion removal
}

\author{
Sadanand Pandey ${ }^{1,2^{*}}$ and James Ramontja ${ }^{1,2}$
}

\begin{abstract}
Background: Polysaccharides are renewable biodegradable natural materials and are accounted for to control the formation of hybrid silica nanocomposites by sol gel process.

Methods: The synthesis of templated silica xerogel essentially includes two critical steps of hydrolysis and polycondensation reaction that are started by catalyst and silica precursor solution. Aside from this Saponification guar-graft-polyacrylonitrile (s-GG-g-PAN) as a copolymer are included in the precursor solution for providing a novel templating environment for silica matrix formation. The s-GG-g-PAN acts as a template for the silica produced in the blended framework because of the hydrogen bonding between the hydroxyl groups at silanols and hydroxyl group and carbonyl groups at the copolymer surface. Connected silanol groups can further hydrolyze and after that take part in the condensation reaction. Accordingly, the s-GG-g-PAN template gets trapped inside the resulting silica system, which on calcining at $900{ }^{\circ} \mathrm{C}$ is lost, producing pores of shape and size of the template.

Results: The surface area and pore volume of the developed templated silica xerogel have been determined. The surface area and pore volume of the template silica xerogel $(\mathrm{H} 900)$ were observed to be $\left(240 \mathrm{~m}^{2} \mathrm{~g}^{-1}\right)$ and $(0.286$ $\mathrm{ccg}^{-1}$ ) respectively. The conditions for the adsorption by adsorbent had been enhanced, and kinetics and thermodynamic studies were performed. The best result in terms of lead adsorption was obtained with templated silica xerogel calcined at $900{ }^{\circ} \mathrm{C}$. The $\% \mathrm{~Pb}^{2+}$ removal is observed to be $96 \%$ when $\mathrm{H} 900$ adsorbent was treated under ideal adsorption states of measurements $0.05 \mathrm{~g}$ dose, $500 \mathrm{mgL}^{-1} \mathrm{~Pb}^{2+}$ concentration, time $2 \mathrm{~h}, \mathrm{pH} 5$ at $30^{\circ} \mathrm{C}$. The adsorption information fitted satisfactorily to Langmuir isotherms, showing unilayer adsorption. In view of the Langmuir model, Qmax was calculated to be $2000 \mathrm{mgg}^{-1}$. Theadsorption demonstrated pseudo-second-order kinetics. The thermodynamic study revealed the endothermic and spontaneous nature of the adsorption. The adsorbent demonstrated good thermal stability and high reusability.
\end{abstract}

Conclusions: The present study highlights the possibility of silica xerogel derived from saponified guar gum-grafted poly (acrylonitrile) toward its potential application as superior adsorbent for removal of $\mathrm{Pb}^{2+}$ from aqueous solution.

Keywords: Biopolymer, Guar gum, Organic-inorganic nanocomposite, Templated xerogel, Environmental pollution, Adsorption, Sol-gel, Lead ion removal

\footnotetext{
*Correspondence: sadanand.au@gmail.com; spandey.uj@gmail.com; spandey@uj.ac.za

'Department of Applied chemistry, University of Johannesburg, P.O. Box 17011, Doornfontein 2028, Johannesburg, Republic of South Africa

${ }^{2}$ Centre for Nanomaterials Science Research, University of Johannesburg, Johannesburg, Republic of South Africa
} 


\section{Background}

Prolonged exposure to heavy metals such as cadmium, copper, lead, nickel, and zinc can cause deleterious health effects in humans (Harrison and Laxen 1981). Lead is one of the heavy metal that is non-essential and occurs naturally in the earth. Today, the potential sources of lead exposure in the drinking water are through leaching from lead-containing pipes, stockpiling batteries, lead purifying, tetraethyl lead assembling, mining, electroplating, ammunition, textiles, printing, painting, metal preparing, and the fired glass commercial enterprises (Schneegurt et al. 2001; Googerdchian et al. 2012). Lead poisoning is a type of metal poisoning caused by lead in the body. Exposure to lead can occur in contaminated air, water, dust, food, or consumer products. In any case, lead in drinking water can likewise bring about an assortment of antagonistic health impacts. The required Occupational Safety and Health Administration (OSHA) Permissible Exposure Limit (PEL) action level for lead in general industry and the construction industry is a time-weighted average (TWA) of $30 \mu \mathrm{g} / \mathrm{m}^{3}$ over 8 -h. The US Environmental Protection Agency (EPA) final rule establishes an action level which is set at $15 \mathrm{\mu gL}^{-1}$. Young children are particularly vulnerable to the toxic effects of lead and can suffer profound and permanent adverse health effects; particularly, it causes moderated development of the brain, learning issues, debilitated hearing, conduct issues (for example, hyperactivity), nerve and/or mind harm, extreme lethargies, and even demise. Lead can even create nephrotoxicity, neurotoxicity, circulatory strain, and unfriendly consequences for the hematological and cardiovascular systems in adult (Harrison and Laxen 1981; Hua et al. 2012).

The high lethality of $\mathrm{Pb}$ ions can bring about genuine biological harm; hence, there is a need to create procedures to wipe out or possibly to extraordinarily reduce the concentration in wastewater preceding discharge into the environment These days, various strategies have been proposed for productive heavy metal removal from wastewaters, including reverse osmosis, ion exchange, electrochemical, evaporation, chemical precipitation, flocculation, and chelation. Frequently, these strategies have high reagent necessities, create secondary pollutants, or are basically wasteful and especially oblige high cost in removing harmful metal ions in trace quantities from solutions (Fu and Wang 2011; Ghorai et al. 2012). Overall the different techniques, adsorption has been perceived as a standout amongst the most economical and effective systems for the removal of the lead from aqueous media because of adaptability in outline and operation, low upkeep expense, and high effectiveness (Mishra et al. 1996). Hence, the adsorption procedure has arrived at the cutting edge as one of the real systems for heavy metal removal from water/wastewater.
The human development has been grouped by paramount material on which the modern innovation is based on the Stone Age, the Iron Age, and now the Polymer Age. This age is properly called the polymer age because of broad utilization of polymers in all domains of life like sensors, water purification, antimicrobial activities, and catalysis (Pandey 2016; Pandey et al. 2013; Pandey et al. 2012; Pandey and Nanda 2016; Pandey and Nanda 2013; Pandey and Ramontja 2016c; Pandey and Ramontja 2016d; Pandey and Mishra 2014; Pandey and Mishra 2013; Pandey and Mishra 2011a, b, c; Singh et al. 2011a, 2011b; Singh et al. 2010a; Singh et al. 2007a; Singh et al. 2007b; Singh et al. 2006). Superparamagnetic nanocomposite of sodium alginate supported tetrasodium thiacalix[4]arene tetrasulfonate ( $\left.\mathrm{Fe}_{3} \mathrm{O}_{4} @ \mathrm{TSTC}[4] \mathrm{AS}-\mathrm{s}-\mathrm{SA}\right)$ (Lakouraj et al. 2014); biodegradable cyclodextrin-based gel (CAM) (Huang et al. 2013); Phanerochaete chryosporium immobilized in alginate gel beads (Arica et al. 2003); magnetic chitosan hydrogel beads (m-CS/PVA/CCNFs) (Zhou et al. 2014); chitosan-g-poly(acrylic acid)/attapulgite/sodium humate (CTS-g-PAA/APT/SH) composite hydrogels (Zhang and Wang 2010); poly(acrylamide)-grafted iron(III) oxide (Pan et al. 2009); Sargassum sp., Ulva sp., and Padina sp., (Sheng et al. 2004); modified orange peel (Feng et al. 2011); palygorskite mud (Chen and Wang 2007); mesoporous silicates (Oshima et al. 2006); and Turkish lignite (Pehlivan and Arslan 2007) have been considered for the removal of the $\mathrm{Pb}^{2+}$ from aqueous solutions.

Commercial polysaccharides can be utilized as sorbents, yet their solvency in water restricts their applications as an adsorbent. Modification of humic acid with silica results in the adsorption of $\mathrm{Pb}^{2+}, \mathrm{Cu}^{2+}$, and $\mathrm{Cd}^{2+}$ (Siliva et al. 2008). Mesoporous organosilicas prepared by direct co-condensation of TEOS (tetraethyl orthosilicate) and other mixed organosilanes, namely, tris[3-(trimethoxysilyl)-propyl]isocyanurate, bis[3(triethoxysilyl)propyl]tetrasulfide, $N$-(3-triethoxysilylpropyl) 4,5-dihydroimidazole, and ureidopropyltrimethoxysilane, have great potential for $\mathrm{Hg}^{2+}$ adsorption (Olkhovyk and Jaroniec 2007). Consequently, the improvement of sol-gel inferred materials with custom-made porosity is an objective in the field of adsorbents and separation media (Pandey and Mishra 2011a).

Templated mesoporous solids can promptly be arranged with organic functionalities coating the silicate structure by co-condensation of TEOS during synthesis and resulting removal of the template. Mesoporous silicates can be union by surfactant (Yang et al. 2008; Tao et al. 2003) or polymer templating routes (Wan and Zhao 2007; Feng et al. 2000). Aside from this, there are certain surfactants, which are known to be toxic to creatures, biological communities, and people, and can build the dispersion of other ecological contaminants. Nowadays, lion's share of the polymers which are utilized for templating is petrochemical based 
and costly, and their removal from silica system is troublesome; also, they are not eco-friendly. Polysaccharides are renewable biodegradable natural materials (Goldstein et al. 1973) and are accounted for to control the formation of hybrid silica nanocomposites by the strategy for sol-gel (Shchipunov and Tat'yana 2004; Shchipunov et al. 2005; Shchipunov 2003), and their removal from the hybrid can be influenced under less drastic conditions when contrasted with the synthetic polymers. A few polysaccharides have been utilized for the synthesis of hybrid materials. But xerogel from the removal of the template from such hybrids and their act as adsorbent has not got much consideration yet. Couple of years back, we had reported novel nanocomposites of vinyl-modified guar gum and silica with amazing capacity to bind $\mathrm{Zn}^{2+}$ (Singh et al. 2008) and $\mathrm{Cd}^{2+}$ (Singh et al. 2009a), where saponified poly(acrylonitrile)-modified guar gum- and poly(acrylamide)-grafted guar were utilized as templates, respectively.

In the present article, we have performed the application of $\mathrm{Pb}^{2+}$ removal by s-GG-g-PAN-silica hybrids (templated silica xerogel). The xerogel obtained by the thermal curing of the templated silica xerogel will be assessed as an adsorbent in the removal of heavy metal ions, $\mathrm{Pb}^{2+}$ from aqueous solution. Near assessment of the s-GG-g-PAN-templated xerogel with blank xerogel (non-templated xerogel) synthesis under comparative conditions by dehydration condensation of TEOS in absence of the template has been undertaken.

\section{Methods}

\section{Chemicals}

Tetraethylorthosilicate $\mathrm{Si}\left(\mathrm{OC}_{2} \mathrm{H}_{5}\right)_{4}(98 \%)$ were purchased from Sigma-Aldrich. Ammonia solution (30\%) $\mathrm{NH}_{4} \mathrm{OH}$, guar gum (GG), acrylonitrile $\left(\mathrm{CH}_{2} \mathrm{CHCN}\right)$, ascorbic acid $\left(\mathrm{C}_{6} \mathrm{H}_{8} \mathrm{O}_{6}\right)$, potassium persulfate $\left(\mathrm{K}_{2} \mathrm{~S}_{2} \mathrm{O}_{8}\right), \mathrm{N}, \mathrm{N}$-dimethylformamide $\left(\left(\mathrm{CH}_{3}\right)_{2} \mathrm{NCH}\right)$, sodium hydroxide $(\mathrm{NaOH})$, hydrochloric acid $(\mathrm{HCl})$, lead(II) nitrate $\left(\mathrm{Pb}\left(\mathrm{NO}_{3}\right)_{2}\right)$, methanol $\left(\mathrm{CH}_{3} \mathrm{OH}\right)$, and ethanol $\left(\mathrm{C}_{2} \mathrm{H}_{5} \mathrm{OH}\right)$ solution were bought from Merck (South Africa) and utilized without further purification.

\section{Instrumental}

The powder X-ray diffraction patterns of biopolymer (guar gum) and templated xerogel (H900) nanocomposite samples were performed by using XRD (Rigaku Ultima IV, $\mathrm{X}$-ray diffractometer, Japan) and were done by employing $\mathrm{Cu}$ Ka radiation of the wavelength of $1.5406 \AA$ with visible lights at $45 \mathrm{kV} / 40 \mathrm{~mA}$. The surface morphology of the templated xerogel (H900) nanocomposite and $\mathrm{Pb}^{2+}$-loaded templated xerogel (H900) nanocomposite was examined by a scanning electron microscopy (SEM) (TESCAN VEGA, Czech Republic) under a 20-kV electron acceleration voltage coupled with energy dispersive (EDS) for elemental examination. Powdering of the nanocomposite was performed by Fritsch Analysette 3 Spartan pulverisette 0 Vibratory Sieve Shaker/Mill (Germany). The concentrations of heavy metal $\left(\mathrm{Pb}^{2+}\right)$ under study were determined by the atomic absorption technique type AA-6800, Shimadzu, Japan.

\section{Synthesis \\ Preparation of the functionalized biopolymer by grafting}

Guar gum-grafted poly(acrylonitrile) (GG-g-PAN) of 25\% grafting can be achieved by following the method and parameter, where GG $(2.0 \mathrm{~g})$ was taken with acrylonitrile $\left(8.8 \times 10^{-2} \mathrm{M}\right)$ and ascorbic acid $\left(2.3 \times 10^{-2} \mathrm{M}\right)$ in $500 \mathrm{~mL}$ water in a 1 - $\mathrm{L}$ flask and thermostated at $(35 \pm 0.2){ }^{\circ} \mathrm{C}$. After $30 \mathrm{~min}$, a known amount of potassium persulfate $\left(20 \times 10^{-3} \mathrm{M}\right)$ was included. The total volume of the reaction mixture was kept constant to $500 \mathrm{~mL}$, and grafting was allowed for $1 \mathrm{~h}$. GG-g-PAN was separated from poly(acrylonitrile) by pouring the reaction mixture into a large quantity of DMF (Singh et al. 2008).

\section{Saponification of the guar-grafted poly(acrylonitrile) (s-GG-g-PAN)}

GG-g-PAN sample with $25 \% \mathrm{G}$ was saponified in aqueous alkali for making silica composites. Grafted samples (2 g) were homogeneously dissolved in $1 \% \mathrm{NaOH}$ at $100{ }^{\circ} \mathrm{C}$ for $1.5 \mathrm{~h}$. After hydrolysis, the samples (s-GG-g-PAN) were precipitated in $600 \mathrm{~mL}$ methanol. Finally, s-GG-g-PAN was washed with methanol $\left(\mathrm{CH}_{3} \mathrm{OH}\right)$ and ethanol $\left(\mathrm{C}_{2} \mathrm{H}_{5} \mathrm{OH}\right)$ solution two to three times and then dried and weighed (Singh et al. 2008). The partial basic hydrolysis of $1.5 \mathrm{~h}$ is performed in order to increase the functionality such as $-\mathrm{CONH}_{2}$ and $-\mathrm{COOH}$ in the copolymer.

\section{Synthesis of composites: s-GG-g-PAN-silica hybrids (templated silica xerogel)}

The synthesis and characterization of s-GG-g-PAN-silica hybrids (templated silica xerogel) had already been published before by our group (Singh et al. 2008). The s-GGg-PAN (1.0 g) was dissolved in $10 \mathrm{~mL}$ of distilled water. Independently, TEOS $(2.5 \mathrm{~mL})$ was likewise dissolved in ethanol $(2.5 \mathrm{~mL})$. A third solution incorporating $1.75 \mathrm{~mL}$ of $12 \mathrm{~N}$ ammonium hydroxide was prepared independently. A short time later, all the three solutions were emptied together into a reaction glass flask and kept under tender blending for more than $18 \mathrm{~h}$ at room temperature to develop monodisperse $\mathrm{SiO}_{2}$ particles inside of the biopolymer/modified biopolymer medium. The following blend was then dissipated in air at $40{ }^{\circ} \mathrm{C}$ (3 h), $60{ }^{\circ} \mathrm{C}(4 \mathrm{~h}), 70{ }^{\circ} \mathrm{C}(2 \mathrm{~h})$, and $80^{\circ} \mathrm{C}$ for $2 \mathrm{~h}$ until a dry material s-GG-g-PAN-silica hybrids (templated silica xerogel) was acquired (H1). H1 was further calcinated in air at 250,500 , and $900{ }^{\circ} \mathrm{C}$ (for $3 \mathrm{~h}$ at every temperature inside a muffle furnace) to obtained templated silica xerogel H250, H500, and H900, respectively. 


\section{Preparation of silica (non-templated silica xerogel)}

The method for the synthesis of non-templated silica xerogel is similar to templated silica xerogel, but nontemplated silica xerogel is prepared in absence of template (s-GG-g-PAN) and designated as S80. The synthesis S80 was also calcinated in air at 250, 500, and $900{ }^{\circ} \mathrm{C}$ (for $3 \mathrm{~h}$ at each temperature inside a muffle furnace) to obtain non-templated silica xerogel S250, S500, and S900, respectively.

\section{Metal ion removal experiments}

$\mathrm{Pb}^{2+}$ sorption investigations were performed by the batch method. Stock solutions of $1000 \mathrm{mgL}^{-1}$ of standardized $\mathrm{Pb}^{2+}$ were prepared from lead salt in DI (deionized) water. Adsorption examinations were carried out using the templated silica xerogel (H900) as adsorbent on a temperature controlled incubator shaker set at $120 \mathrm{rpm}$ (revolutions per minute) kept up at $30{ }^{\circ} \mathrm{C}$ for $2 \mathrm{~h}$. Here, known measure of adsorbent was completely mixed with $50 \mathrm{~mL}$ of individual $\mathrm{Pb}^{2+}$ solutions, whose concentrations and $\mathrm{pHs}$ were beforehand known. As we realize that $\mathrm{pH}$ assumes a vital part in metal ion binding, thus, $\mathrm{pH}$ of the reaction mixture was initially adjusted using either $\mathrm{HCl}$ or $\mathrm{NaOH}(1 \mathrm{M})$. The $\mathrm{pH}$ measurements were made with OHAUS starter 2100 (USA). After the flask was shaken for the desired time, the suspensions were filtered through Whatman $0.45 \mathrm{~mm}$ filter paper and the filtrates after suitable dilutions were analyzed for $\mathrm{Pb}^{2+}$ concentration utilizing using atomic absorption spectrophotometer (AAS) at $217 \mathrm{~nm}$ utilizing a slit width of $1 \mathrm{~nm}$. Control tests demonstrated that no sorption occurred on either glass or filtration frameworks. All the adsorption examination was performed in triplicate, and there average was reported. For enhancing the adsorption, one parameter was change at a time, keeping all the other parameters constant.

The measure of metal ions adsorbed per gram of the adsorbent was computed by the difference between the initial and the final readings using the following (Eq. 1).

$$
q e=(\mathrm{Co}-\mathrm{Ce}) \times \frac{V}{W}
$$

where $q_{e}$ is the measure of the $\mathrm{Pb}^{2+}$ adsorbed $\left(\mathrm{mgg}^{-1}\right)$ on the adsorbent, $C_{o}$ is the beginning concentration of $\mathrm{Pb}^{2+}\left(\mathrm{mgL}^{-1}\right), C_{e}$ is the equilibrium concentration of $\mathrm{Pb}^{2+}$ in solution $\left(\mathrm{mgL}^{-1}\right), V$ is the volume of the solution utilized (L), and $W$ is the weight of the adsorbent utilized The $\mathrm{pH}$, introductory concentration of $\mathrm{Pb}^{2+}$, adsorbent dosage, and contact time were varied, one at a time keeping the other parameters fixed.

Thirty milliliters of the various background electrolytes $\left(\mathrm{KCl}, \mathrm{KNO}_{3}, \mathrm{~K}_{2} \mathrm{SO}_{4}\right)$ in three concentrations of 0.1 , 0.01 , and $0.001 \mathrm{~mol} \mathrm{~L}^{-1}$ containing $500 \mathrm{mg} \mathrm{L}^{-1} \mathrm{~Pb}^{2+}$ were separately added to $0.05 \mathrm{~g}$ of adsorbent. The $\mathrm{pH}$ of these solutions was not adjusted to avoid negating the $\mathrm{pH}$ effects of the electrolytes. These solutions were agitated in an orbital shaker for $2 \mathrm{~h}, 120 \mathrm{rpm}$, and at $30{ }^{\circ} \mathrm{C}$. The supernatants collected were analyzed for $\mathrm{Pb}^{2+}$.

In order to determine the reusability of the templated silica xerogel (H900) adsorbent, $\mathrm{Pb}^{2+}$ was stripped off from the used adsorbent using $\mathrm{H}_{2} \mathrm{SO}_{4}$ and reused. To optimize the concentration of the acid required for the quantitative stripping of the loaded $\mathrm{Pb}^{2+}$, experiments were carried out with varying concentrations of $\mathrm{H}_{2} \mathrm{SO}_{4}$ ranging from 0.001 to $1 \mathrm{M}$, where efficient desorption could be achieved using $0.01 \mathrm{~N} \mathrm{H}_{2} \mathrm{SO}_{4}$ in $2 \mathrm{~h}$. Templated silica xerogel (H900) adsorbent (50 mg) was

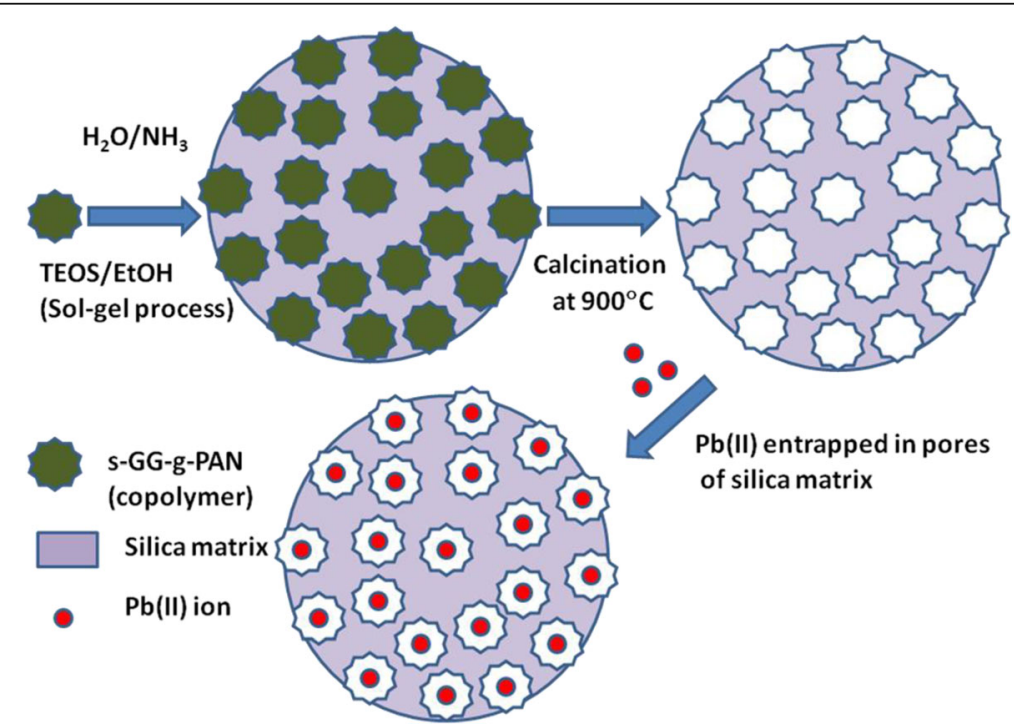

Fig. 1 Schematic diagram of templated silica xerogel synthesis and binding of $\mathrm{Pb}^{2+}$ in aqueous medium 
placed in the $25 \mathrm{~mL}$ of $0.01 \mathrm{~N} \mathrm{H}_{2} \mathrm{SO}_{4}$, stirred at $100 \mathrm{rpm}$ for $2 \mathrm{~h}$ at $30{ }^{\circ} \mathrm{C}$, centrifuged, and dried.

\section{Results and discussion}

The synthesis of templated silica xerogel essentially includes two critical steps of hydrolysis and polycondensation reaction that are started by catalyst and silica precursor solution. Aside from this, s-GG-g-PAN as a copolymer is included in the precursor solution for providing a novel templating environment for silica matrix formation. The s-GG-g-PAN acts as a template for the silica produced in the blended framework because of the hydrogen bonding between the hydroxyl groups at silanols and hydroxyl group and carbonyl groups at the copolymer surface. Connected silanol groups can further hydrolyze and after that take part in the condensation reaction. Accordingly, the sGG-g-PAN template gets trapped inside the resulting silica system, which on calcining at $900{ }^{\circ} \mathrm{C}$ is lost, producing pores of shape and size of the template. The overall schematic diagram of templated silica xerogel synthesis and binding of $\mathrm{Pb}^{2+}$ in aqueous medium is shown in Fig. 1.

To examine the impact of calcination, $\mathrm{H} 1$ was calcinated in air at 250,500 , and $900{ }^{\circ} \mathrm{C}$ (for $3 \mathrm{~h}$ at every temperature inside a muffle furnace) to obtained templated silica xerogel H250, H500, and H900, separately, and they were tested for $\mathrm{Pb}^{2+}$ removal (Additional file 1: Table S1). Additional file 1: Table S1 demonstrates that the adsorption of $\mathrm{Pb}^{2+}$ takes after the order: $\mathrm{H} 900>\mathrm{H} 500>$ $\mathrm{H} 250>\mathrm{H} 80$ > S900. The H900 having most extreme binding is indicated to have the high surface area $\left(240 \mathrm{~m}^{2} \mathrm{~g}^{-1}\right)$ and the pore volume $\left(0.286 \mathrm{ccg}^{-1}\right)$ supporting its sorption capacity. The binding additionally relies on the extraordinary shapes of this mesopore, which are dictated by packing mode and by the size distribution of the constituent particles (Yang et al. 2007). The porosity present in the adsorbent has all the earmarks of being basically in charge of the adsorption, where the pore size is confined by the copolymer template like perception in $\mathrm{Zn}^{2+}$ removal. It was likewise delineated from the outcome that the calcining of xerogel at different temperature results in a critical impact on the physical attributes and thus on the adsorption properties of the composites.

The XRD of GG and non-templated silica xerogel shows amorphous nature. While the XRD of the templated silica xerogel (H900) demonstrates the crystalline nature as obvious by the vicinity of a few crystalline peaks (indicated in Fig. 2, Additional file 1: Table S2). Out of which, six extreme sharp peaks showed up at $d=4.29611(2 \theta=20.6577), d=4.07286$ $(2 \theta=21.8035), d=3.80153(2 \theta=23.3809), d=3.24161$ $(2 \theta=27.4926), \quad d=2.96154 \quad(2 \theta=30.1513), \quad$ and $d=$ $2.48391(2 \theta=36.1316)$. These sharp peaks resemble the $\alpha$-tridymite and polymorph of silicon oxide by Phase reg. detail: ICDD (PDF2010), and DB card number: 01-086-0681. This implies organic copolymer which acts as a template result in silica crystallization and helps in change of one crystal structure to another having same chemical composition (polymorph) when treated at $900{ }^{\circ} \mathrm{C}$.

BET examination of $\mathrm{H} 900$ was performed and compared with H80, S80, and S900 (Table 1). It demonstrates the high surface area $\left(240 \mathrm{~m}^{2} \mathrm{~g}^{-1}\right)$ and the pore volume $\left(0.286 \mathrm{ccg}^{-1}\right)$ of templated silica xerogel (H900) test. While if there should arise, an occurrence of templated silica xerogel (H80) demonstrates the surface area $\left(6.2 \mathrm{~m}^{2} \mathrm{~g}^{-1}\right)$ and the pore volume $\left(0.026 \mathrm{ccg}^{-1}\right)$ and nontemplated silica xerogel (S900) demonstrates the surface area $\left(4 \mathrm{~m}^{2} \mathrm{~g}^{-1}\right)$ and the pore volume $\left(0.096 \mathrm{ccg}^{-1}\right)$. In this way, it is affirmed that templated silica xerogel (H900) demonstrates the most extreme surface region. As a result of these critical properties, result in high adsorption of $\mathrm{Pb}^{2+}$ is onto templated silica xerogel (H900).

The effect of the template (s-GG-g-PAN) on the structure of silica matrices was also analyzed by SEM images, describing templated xerogel (H900) at two different magnifications $(\times 2 \mathrm{~K}$ and $\times 5 \mathrm{~K})$, and is displayed in Fig. 3a, b. From the SEM images, it can be predicted that the
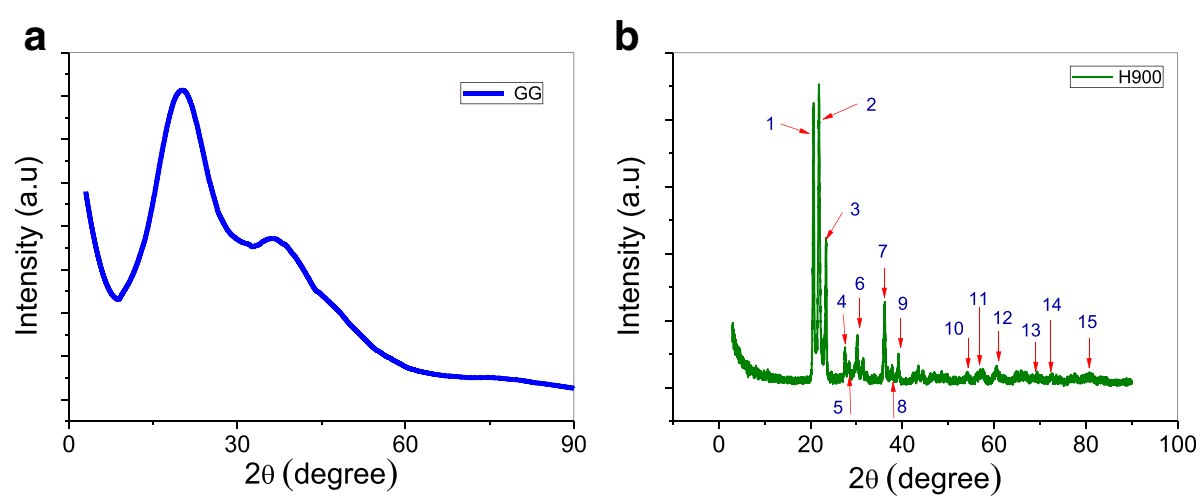

Fig. 2 XRD of a guar gum and $\mathbf{b}$ templated silica xerogel (H900) 
Table 1 Surface parameters of the templated silica xerogel ( $\mathrm{H80}, \mathrm{H} 900)$ and non-templated silica xerogel (S80, S900)

\begin{tabular}{llc}
\hline Samples & $\begin{array}{l}\text { BET surface area } \\
\left(\mathrm{m}^{2} \mathrm{~g}^{-1}\right)\end{array}$ & $\begin{array}{l}\text { BJH pore volume } \\
\left(\mathrm{cm}^{3} \mathrm{~g}^{-1}\right)\end{array}$ \\
\hline $\begin{array}{l}\text { Templated silica } \\
\text { xerogel (H80) }\end{array}$ & 6.2 & 0.026 \\
$\begin{array}{l}\text { Templated silica } \\
\text { xerogel (H900) }\end{array}$ & $\mathbf{2 4 0}$ & $\mathbf{0 . 2 8 6}$ \\
$\begin{array}{l}\text { Silica xerogel (S80) } \\
\text { Silica xerogel (S900) }\end{array}$ & 7.5 & 0.136 \\
\hline
\end{tabular}

H900 sample use for detail study are in bold

matrices obtained are more homogeneous in size, with a spongy appearance. The SEM images also clearly show the surface porosity in the templated xerogel (H900); this is because of the presence of template calcined at $900{ }^{\circ} \mathrm{C}$. The affirmation of $\mathrm{Pb}^{2+}$ adsorption onto templated silica xerogel (H900) was performed by surface morphology study and by SEM at two different magnifications $(\times 2 \mathrm{~K}$ and $\times 5 \mathrm{~K})$ (Fig. $3 \mathrm{c}, \mathrm{d})$. The images demonstrate the stuffing of lead inside the pores of silica matrix, and final affirmation was performed by EDS where the vicinity of $\mathrm{Pb}$ content is found along with $\mathrm{Si}$ and $\mathrm{O}$ (Fig. 4a), while in case of templated xerogel (H900), there is no peak of $\mathrm{Pb}$ observed (Fig. 4b).

\section{Optimization of $\mathrm{Pb}^{2+}$ removal}

Since the greatest $\mathrm{Pb}^{2+}$ binding was observed for templated silica xerogel (H900), adsorption was further upgraded with templated silica xerogel (H900) by varying one adsorption parameter at a time keeping all the others fixed.

\section{Effect of $\mathrm{pH}$ on $\mathrm{Pb}^{2+}$ adsorption}

Figure 5 a demonstrates that the $\mathrm{Pb}^{2+}$ adsorption capacity and removal proficiency increases with the $\mathrm{pH}$ value from 1.0 to 6.0. The adsorption increases with an increment of $\mathrm{pH}$ of the solution in the extent 1.0-5.0. A pH of 5-6 was observed to be an ideal for $\mathrm{Pb}^{2+}$ adsorption on templated silica xerogel. At $500 \mathrm{mgL}^{-1}$ introductory $\mathrm{Pb}^{2+}$ concentration, utilizing $50 \mathrm{mg}$ adsorbent, $\mathrm{Pb}^{2+}$ removal increased from 62 to $480 \mathrm{mgL}^{-1}$ with the increment in $\mathrm{pH}$ from 1.0 to 5.0 (Fig. 5a).

The removal of $\mathrm{Pb}^{2+}$ from aqueous solution by templated silica xerogel (H900) was observed to be exceptionally subject to the solution $\mathrm{pH}$ value which influences the qualities of the adsorbent and the adsorbate. Despite the fact that the final $\mathrm{pH}$ varied, the final $\mathrm{pH}$ of all solution displayed slight increment. At $\mathrm{pH}$ 2.0, adsorption impact is extremely weak because of the competition of $\mathrm{H}_{3} \mathrm{O}^{+}$. This is affirmed by a slight increment of initial $\mathrm{pH}\left(\mathrm{pH}_{0}\right)(\mathrm{Han}$ et al. 2006; Eiden et al.
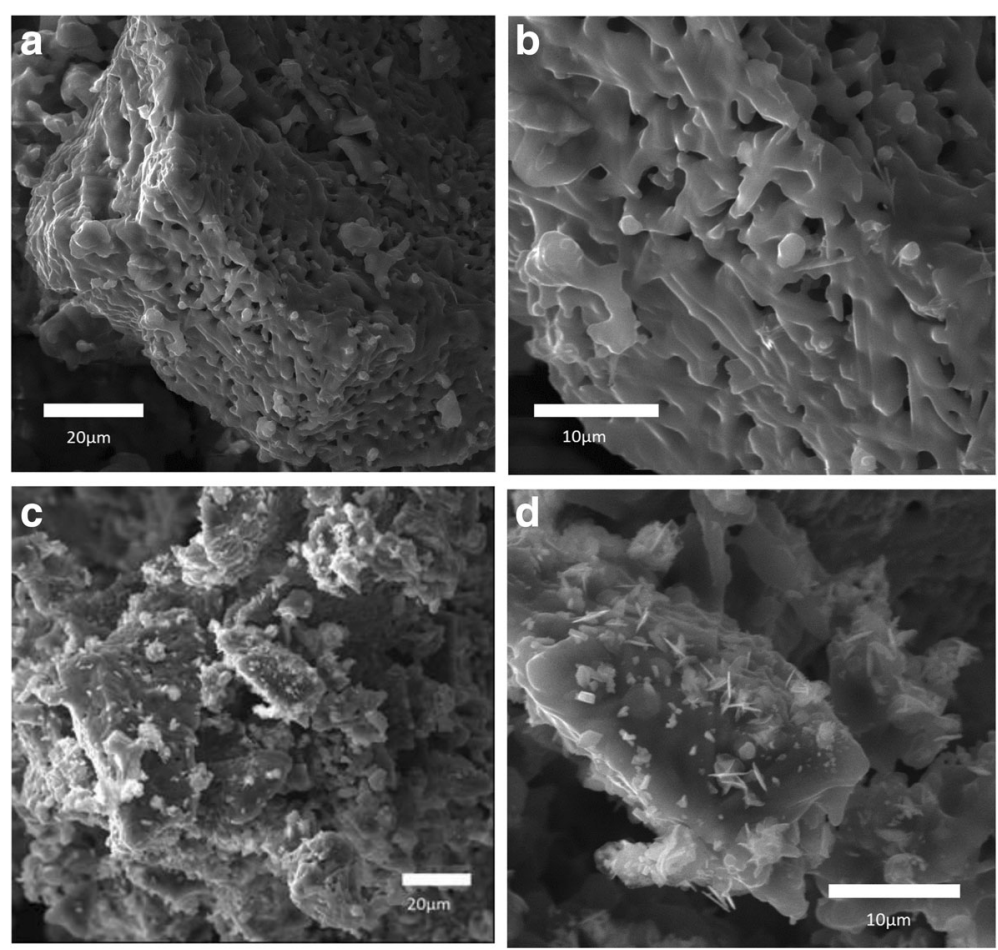

Fig. 3 SEM image of templated silica xerogel (H900) at magnifications $\mathbf{a} \times 2 \mathrm{~K}$ and $\mathbf{b} \times 5 \mathrm{~K}$. SEM image of $\mathrm{Pb}^{2+}$-loaded templated silica xerogel ( $\mathrm{H} 900)$ at magnifications $\mathbf{c} \times 2 \mathrm{~K}$ and $\mathbf{d} \times 5 \mathrm{~K}$ 

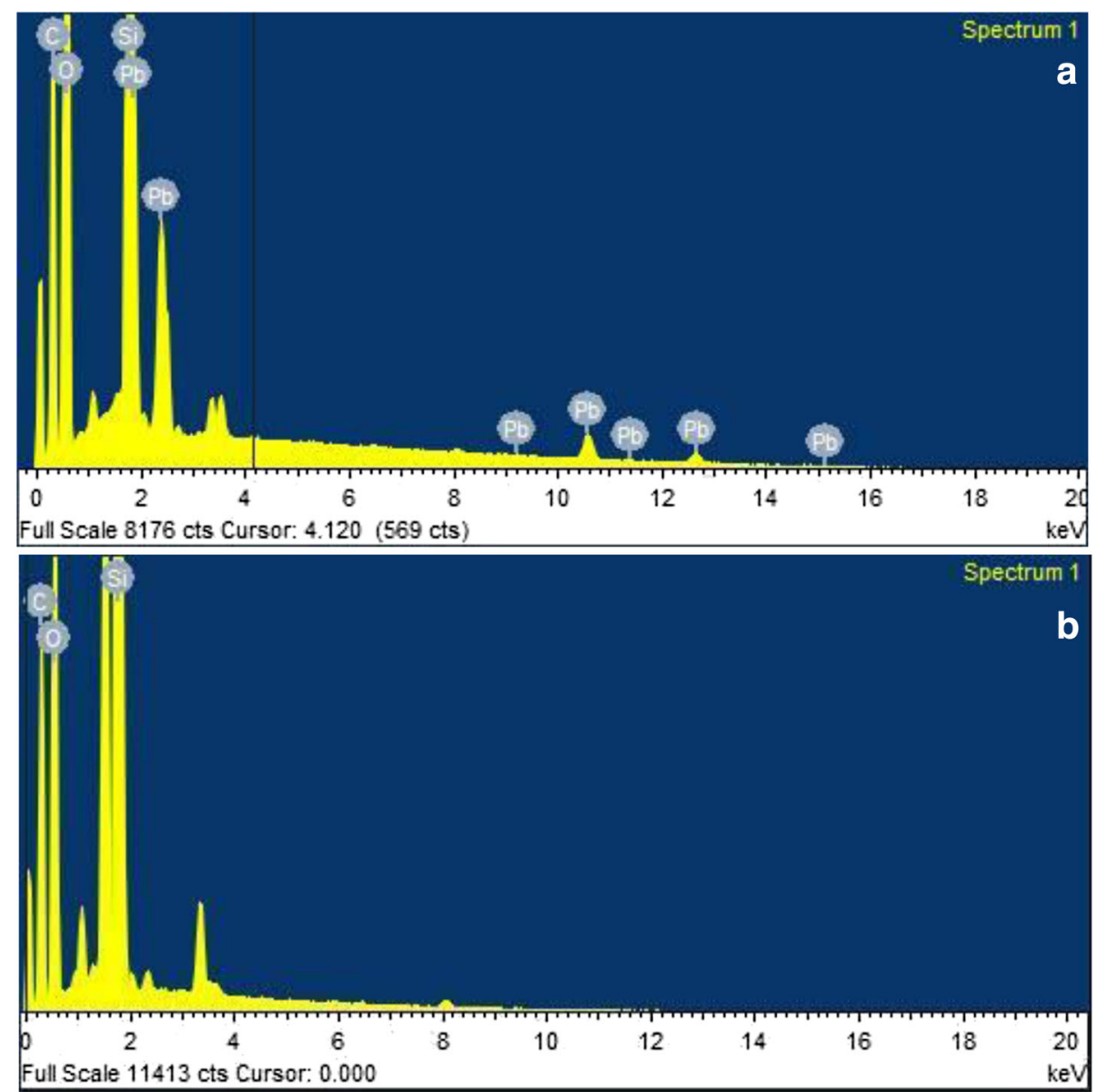

Fig. 4 EDS of a $\mathrm{Pb}^{2+}$-loaded templated silica xerogel (H900) and $\mathbf{b}$ templated silica xerogel (H900)

1980). At higher $\mathrm{pH}$, increment of $\mathrm{pH}$ of the aqueous solution prompts the hydrolysis of lead species with known equilibrium constant is shown in Eqs. (2) and (3) (Kovac ${ }^{2}$ evic' et al. 2000):

$$
\begin{aligned}
& \mathrm{Pb}^{2+}+\mathrm{OH}^{-} \rightarrow \mathrm{PbOH}^{+} \\
& \mathrm{PbOH}^{+}+\mathrm{OH}^{-} \rightarrow \mathrm{Pb}(\mathrm{OH})_{2}
\end{aligned}
$$

In aqueous solutions of $\mathrm{pH}$ under $6, \mathrm{~Pb}^{2+}$ ions exist as either $\mathrm{Pb}^{2+}$ or $\mathrm{Pb}(\mathrm{OH})^{+}$or both. However, the formation of $\mathrm{Pb}^{2+}$ hydrolysis products begins to happen at $\mathrm{pH}$ values somewhere around 6 and 7 , and this achieves insoluble precipitation of $\mathrm{Pb}(\mathrm{OH})_{2}, \mathrm{~Pb}(\mathrm{OH})_{3}^{-}$, and $\mathrm{Pb}(\mathrm{OH})_{4}^{2-}$. Possibly, templated silica xerogel (H900) may carry on as negatively charged surface. These are in charge of improved adsorption of positively charged $\mathrm{Pb}^{2+}$ and $\mathrm{Pb}(\mathrm{OH})^{+}$through electrostatic interaction and surface complexation model at higher $\mathrm{pH}$ (Pretorius and Linder 2001).

The equilibrium $\mathrm{pH}\left(\mathrm{pH}_{\mathrm{e}}\right)$ values were marginally higher than initial $\mathrm{pH}$ at $\mathrm{pH}=1-5$ (Additional file 1: Table S3). This is an aftereffect of competition between
$\mathrm{Pb}^{2+}$ ions and $\mathrm{H}_{3} \mathrm{O}^{+}$for binding sites. So in templated silica xerogel, negatively charge surface-bound hydroxyl groups get to be accessible to heavy metal ions for coordination. Low $\mathrm{pH}$ of solution expands $\mathrm{H}_{3} \mathrm{O}^{+}$concentration and strengthens the competition between $\mathrm{H}_{3} \mathrm{O}^{+}$ and heavy metal ions for complexation sites. Be that as it may, at $\mathrm{pH} \geq 6.0$, the $q_{e}$ estimations of $\mathrm{Pb}^{2+}$ diminished with an increment of $\mathrm{pH}$, inferable from the interaction between $\mathrm{OH}^{-}$and $\mathrm{Pb}^{2+}$ ions in the solution to form $\mathrm{Pb}(\mathrm{OH})_{2}$. This reveals that adsorption of heavy metals on templated silica xerogel was complexation, in particular non-stoichiometric, as opposed to ion-exchange adsorption mode. Thus, adsorption mechanisms of heavy metals by templated silica xerogel are may be possibly because of complexation between heavy metal ions and templated silica xerogel fundamentally at $\mathrm{pH}=1-5$ and hydrolysis adsorption and surface micro-precipitation at $\mathrm{pH}=6-7$ as per literature. It was clearly affirmed from researchers (Escudero et al. 2013), who have reported the quantitative chemical examination of $\mathrm{Pb}$ (dissolved and precipitated). The author has depicted the $\mathrm{Pb}$ broke down and $\mathrm{Pb}$ accelerated are 97.3 and $2.7 \%$ separately at $\mathrm{pH}$ 5, 

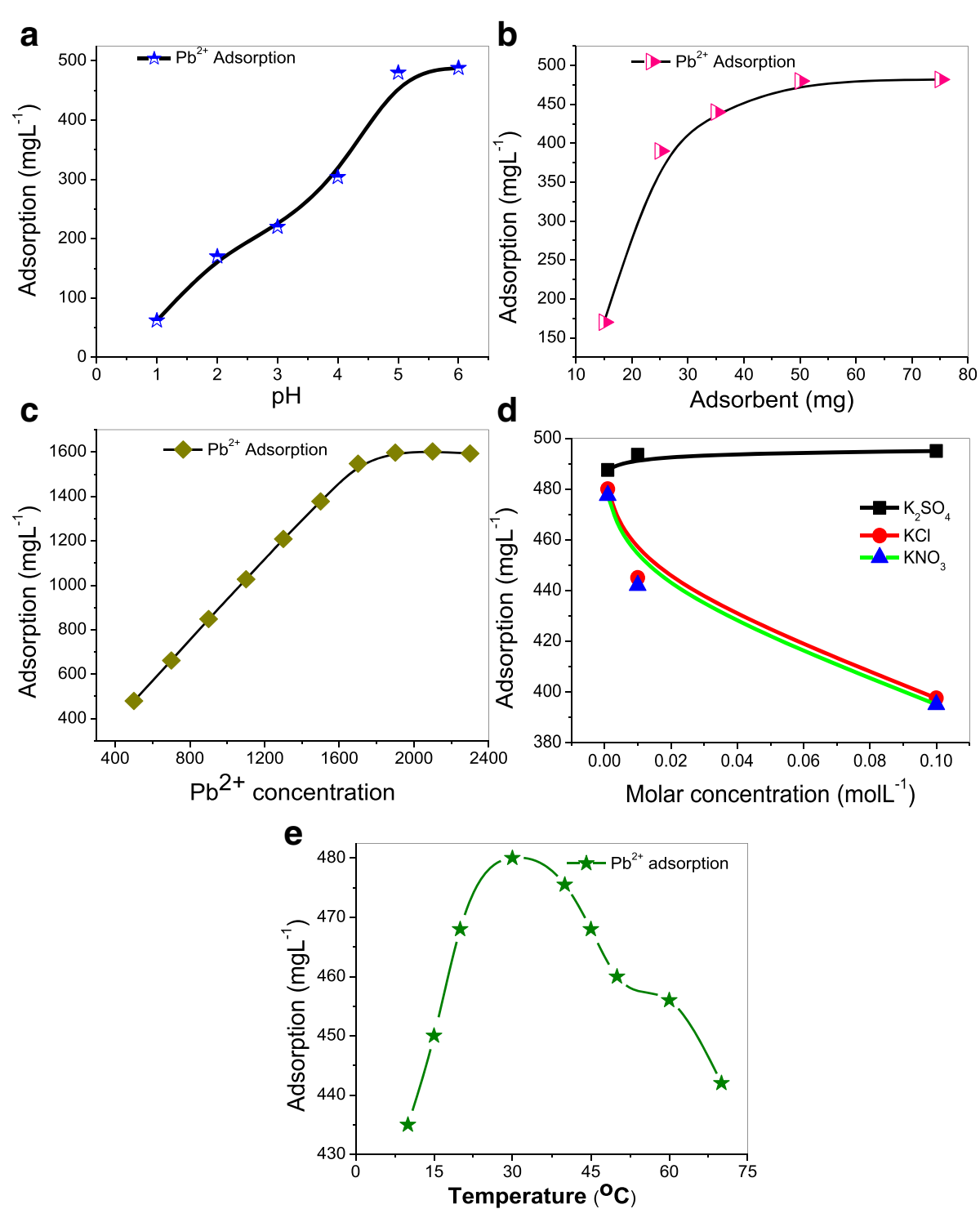

Fig. $5 \mathrm{~Pb}^{2+}$ adsorption by templated silica xerogel ( $\left.\mathrm{H} 900\right)$ with a effect of $\mathrm{pH}$, $\mathbf{b}$ effect of adsorbent dose, $\mathbf{c}$ effect of initial $\mathrm{Pb}^{2+}$ concentrations, d effect of electrolytes, and $\mathbf{e}$ effect of temperature

1.9 and $98.1 \%$ at $\mathrm{pH} 8$, and 0 and $100 \%$ at $\mathrm{pH} 11$ from $40 \mathrm{mgL}^{-1}$ of lead solution. Therefore, it affirms there is irrelevant or no precipitation at $\mathrm{pH} 5$.

\section{Effect of adsorbent dose}

The removal of $\mathrm{Pb}^{2+}$ increases from 170 to $482 \mathrm{mgL}^{-1}$ by expanding the adsorbent dose from 15 to $75 \mathrm{mg}$ in $50 \mathrm{~mL}$ of $500 \mathrm{mgL}^{-1}$ initial $\mathrm{Pb}^{2+}$ concentration at $30{ }^{\circ} \mathrm{C}$, rpm 120, contact time $2 \mathrm{~h}$, and $\mathrm{pH} 5$. This increase is because at the higher dose of adsorbent, more binding sites are available due to increased surface area (Fig. 5b).

\section{Effect of $P b^{2+}$ concentration}

Effect of $\mathrm{Pb}^{2+}$ concentration studies were carried out by taking concentration in the range 500 to $2300 \mathrm{mg} \mathrm{L}^{-1}$ at temperature $30{ }^{\circ} \mathrm{C}$ (Fig. 5c). It was observed that increase in the adsorption is sharp initially followed by slow increase leading to saturation. Initially due to more availability of $\mathrm{Pb}^{2+}$, adsorption increases which later on after the saturation of the adsorption sites at the adsorbent, adsorption gradually decreases.

\section{Effect of ionic nature and strength on $\mathrm{Pb}^{2+}$ adsorption}

The vicinity of salts may meddle with the lead adsorption. The effect of inorganic anion on the adsorption of $\mathrm{Pb}^{2+}$ onto templated silica xerogel (H900) was studied. It was observed that more $\mathrm{Pb}$ was adsorbed in the presence of $\mathrm{SO}_{4}^{2-}$ whereas $\mathrm{NO}_{3}^{-}$and $\mathrm{Cl}^{-}$gave almost equal $\mathrm{Pb}$ adsorption. Notwithstanding, the $\mathrm{Pb}$ adsorption rate of $\mathrm{H} 900$ was diminished in the presence of $\mathrm{Cl}^{-}$and $\mathrm{NO}_{3}^{-}$ 
compared to $\mathrm{SO}_{4}^{2-}$. There was a stronger attraction between $\mathrm{Pb}^{2+}$ and the adsorbent in the vicinity of $\mathrm{SO}_{4}^{2-}$ than alternate anions which indicate almost equal attraction. Increasing the ionic strength of the anions (from 0.001 to $0.1 \mathrm{~mol} \mathrm{~L}^{-1}$ ) influenced the adsorption of lead. In the vicinity of $\mathrm{SO}_{4}^{2-}, \mathrm{Pb}$ adsorption increased with increasing ionic strength but the reverse was the case in the presence of $\mathrm{Cl}^{-}$and $\mathrm{NO}_{3}^{-}$. In the vicinity of anions, the distribution coefficient $(\mathrm{Kd})$ values decreased with increase in ionic strength aside from $\mathrm{SO}_{4}^{2-}$. At ionic strength of $0.001 \mathrm{~mol} \mathrm{~L}^{-1}, \mathrm{SO}_{4}^{2-}, \mathrm{Cl}^{-}$, and $\mathrm{NO}_{3}^{-}$were $487.5,480$, and $477.5 \mathrm{mgL}^{-1}$ in $\mathrm{H} 900$ adsorbent, respectively, while at $0.01 \mathrm{~mol} \mathrm{~L}^{-1}, \mathrm{SO}_{4}^{2-}, \mathrm{Cl}^{-}$, and $\mathrm{NO}_{3}^{-}$were 493.5, 445, and $442 \mathrm{mgL}^{-1}$ in $\mathrm{H} 900$ adsorbent, respectively (Fig. 2d), and at $0.1 \mathrm{~mol} \mathrm{~L}^{-1}, \mathrm{SO}_{4}^{2-}, \mathrm{Cl}^{-}$, and $\mathrm{NO}_{3}^{-}$ were 495, 397.5, and $395 \mathrm{mgL}^{-1}$ in $\mathrm{H} 900$ adsorbent, respectively (Fig. 5 d). Thus, we can say that in the $\%$ adsorption of $\mathrm{Pb}^{2+}$ at $0.1 \mathrm{~mol} \mathrm{~L}{ }^{-1}, \mathrm{SO}_{4}^{2-}, \mathrm{Cl}^{-}$, and $\mathrm{NO}_{3}^{-}$ were $99,79.5$, and $79 \%$ in templated silica xerogel (H900) adsorbent, respectively. It demonstrated that increasing the ionic strength of $\mathrm{SO}_{4}^{2-}$ increased the affinity of $\mathrm{Pb}^{2+}$ for $\mathrm{H} 900$ adsorbent, while increased the affinity of $\mathrm{Cl}^{-}$and $\mathrm{NO}_{3}^{-}$decreased the affinity of $\mathrm{Pb}^{2+}$ for templated silica xerogel (H900) adsorbent.

\section{Effect of temperature}

The effect of temperature on the adsorption was studied in the range $10-70{ }^{\circ} \mathrm{C}$ at the initial concentration of $\mathrm{Pb}^{2+}$ $500 \mathrm{mgL}^{-1}$, rpm 120, contact time $2 \mathrm{~h}$, and $\mathrm{pH}$ 5. It was observed that initial increment in the adsorption with the increment in the temperature from 10 to $30{ }^{\circ} \mathrm{C}$ demonstrates that adsorption is endothermic nature (Fig. 5e). However, at the temperature more noteworthy than $30{ }^{\circ} \mathrm{C}$, a slight decrease in adsorption was observed from 40 to $70{ }^{\circ} \mathrm{C}$. The adsorption decreases from 96 to $88.4 \%$ with an increase in temperature from 30 to $70{ }^{\circ} \mathrm{C}$. As we know that the physical adsorption decreases with increasing temperature, and chemical adsorption increases as the temperature increases, in solution, the molecule or adsorbate is not free like in the gas phase; it is surrounded by solvent molecules. Such molecules to be adsorbed on a surface or in a cage (silica) should break its interaction with solvent molecules; it requires energy (endothermic process). In such a case, there is the possibility that the energy required to break interactions with the solvent be higher than the energy released during its adsorption on the surface. In such a case, adsorption is favored with temperature and the whole process be endothermic (favored with temperature). While the possible reason for the decrease in adsorption at certain temperature may be because if temperatures are high and are capable of initiating a back reaction from the chemisorbed state, chemisorption will as well drop by increasing temperature. This is the case if your chemisorption process involves a covalent-reversible reaction. Basically, the elevated temperature makes the chemisorption (in a whole) a physisorption process.

\section{Adsorption isotherm studies}

Adsorption isotherms are helpful to advance the attempt of templated silica xerogel (H900) as an adsorbent. Therefore, exact comparisons are important for adsorption information understanding and expectations. The accompanying articulations of a straight line were utilized and found by method for scientific transformation of isotherms.

\section{For Langmuir isotherm}

The Langmuir isotherm theory infers monolayer coverage of adsorbate over a homogenous adsorbent surface (Langmuir 1916). Langmuir isotherm can be given as Eq. (4) as follows:

$$
\frac{C_{e}}{q_{e}}=\frac{1}{b Q_{o}}+\frac{C_{e}}{Q_{o}}
$$

where $C_{e}$ is the equilibrium concentration $\left(\mathrm{mgL}^{-1}\right)$ and $q_{e}$ the sum adsorbed at equilibrium $\left(\mathrm{mgg}^{-1}\right)$. The Langmuir constants $Q_{o}\left(\mathrm{mgg}^{-1}\right)$ speak to the monolayer adsorption capacity, and $b\left(\mathrm{Lmg}^{-1}\right)$ relates the heat of adsorption.

The $R_{L}$ is a dimensionless constant referred to as separation factor. $R_{L}$ is calculated using the following Eq. (5):

$$
R_{L}=\frac{1}{1+b C_{o}}
$$

where $C_{o}$ is the introductory $\mathrm{Pb}^{2+}$ concentration $\left(\mathrm{mgL}^{-1}\right)$. If $R_{L}$ values lie somewhere around 0 and 1 , the adsorption is favorable.

\section{For Freundlich isotherm}

The Freundlich isotherm portrays the heterogeneous surface energies by multilayer adsorption and is communicated in linear form as provided in Eq. (6) (Freundlich 1907):

$$
\ln q_{e}=\ln K_{f}+\frac{1}{n} \ln C_{e}
$$

where $K_{f}$ demonstrates adsorption limit $\left(\mathrm{mgg}^{-1}\right)$ and " $\mathrm{n}$ " an observational parameter related to the intensity of adsorption, which shifts with the heterogeneity of the adsorbent. The more prominent the estimations of the $n$, better is the favorability of the adsorption.

\section{For Temkin isotherm}

This sort of isotherm contains a variable that obviously and definitely portrays adsorbent-adsorbate interactions. By disregarding the great degree low and huge estimation of concentrations, the model expects that heat of adsorption (the function of temperature) of all molecules in the 

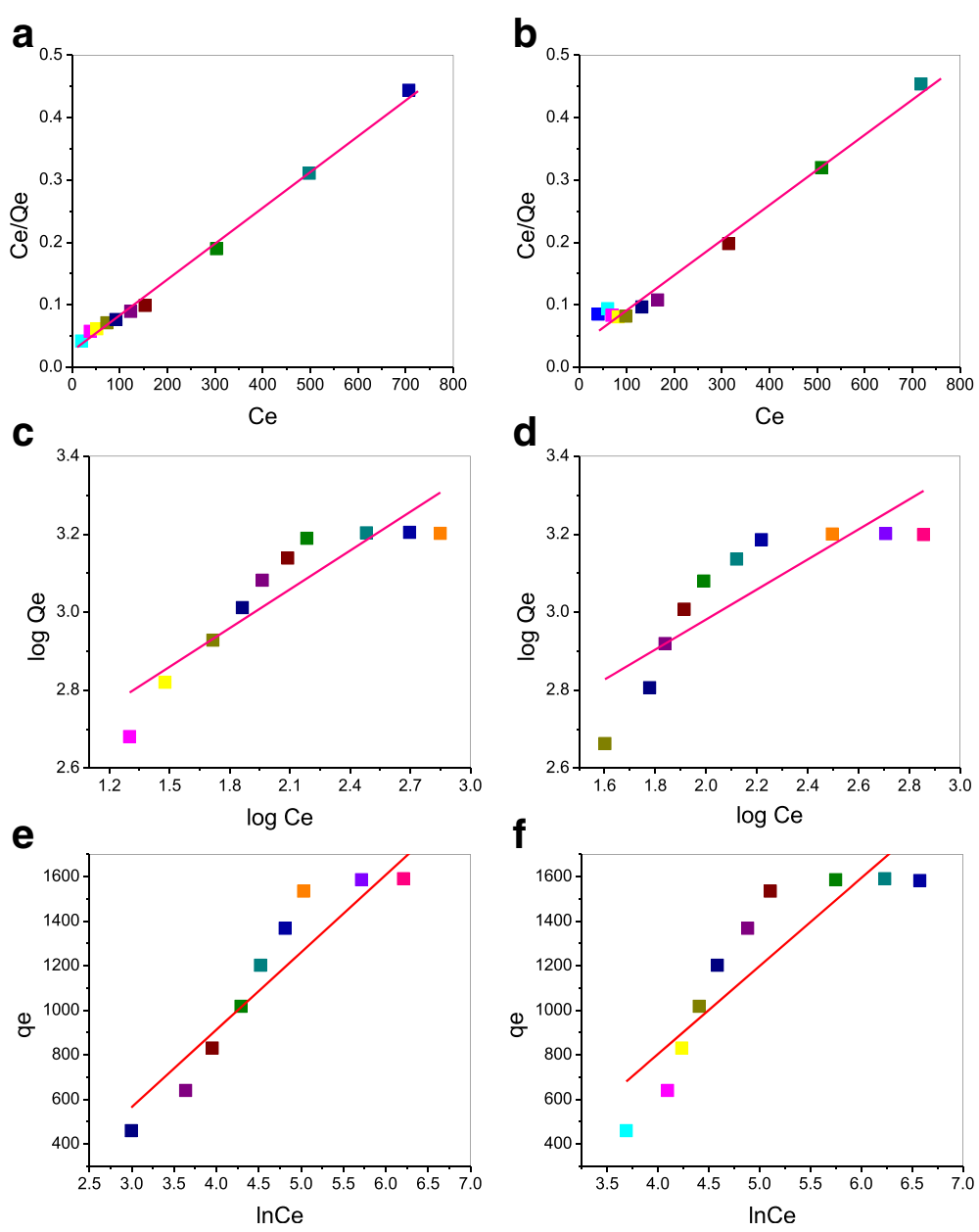

Fig. 6 Adsorption isotherm. Langmuir adsorption isotherm at $\mathbf{a} 30^{\circ} \mathrm{C}$ and $\mathbf{b} 15^{\circ} \mathrm{C}$. Freundlich adsorption isotherm at $\mathbf{c} 30^{\circ} \mathrm{C}$ and $\mathbf{d} 15{ }^{\circ} \mathrm{C}$. Temkin adsorption isotherm at $\mathbf{e} 30^{\circ} \mathrm{C}$ and $\mathbf{f} 15^{\circ} \mathrm{C}$

Table 2 Langmuir, Freundlich, and Temkin constants at 30 and $15^{\circ} \mathrm{C}$

\begin{tabular}{lllll}
\hline Temperature $\left({ }^{\circ} \mathrm{C}\right)$ & \multicolumn{4}{l}{ Adsorption isotherm model } \\
\hline \multicolumn{5}{c}{ Langmuir isotherm } \\
30 & $Q_{\max }$ & $b\left(\mathrm{Lmg}^{-1}\right)$ & $R^{2}$ \\
15 & 2000 & 0.0208 & 0.995 \\
& 2000 & 0.0135 & 0.983 & \\
& & Freundlich isotherm & & \\
30 & $n$ & $K_{f}$ & $R^{2}$ & \\
15 & 3.0184 & 10.676 & 0.832 & \\
& 2.5953 & 9.1211 & 0.7152 & \\
& & Temkin isotherm & & 0.869 \\
30 & $A_{T}\left(\mathrm{Lg}^{-1}\right)$ & $b_{T}$ & $B\left(\mathrm{Jmol}^{-1}\right)$ & $R^{2}$ \\
15 & 3.9439 & 7.255 & 347.40 & 0.794 \\
\hline
\end{tabular}

layer would diminish linearly instead of logarithmic with coverage (Tempkin and Pyzhev 1940). The comparison suggests that its inference is portrayed by a uniform distribution of binding energies (up to some maximum binding energy) and was the amount sorbed $q_{e}$ against $\ln C_{e}$ and the constants were resolved from the slope and intercept. The model is provided by Eqs. (7, 8, and 9) as follows:

$$
\begin{aligned}
& q_{e}=\frac{R T \ln A_{T}}{b_{T}}+\frac{R T}{b} \ln C_{e} \\
& B=\frac{R T}{b_{T}} \\
& q_{e}=B \ln A_{T}+B \ln C_{e}
\end{aligned}
$$

where $A_{T}$ is the Temkin isotherm equilibrium binding constant $\left(\mathrm{Lg}^{-1}\right), b_{T}$ is the Temkin isotherm constant, $R$ is the universal gas constant $\left(8.314 \mathrm{Jmol}^{-1} \mathrm{~K}^{-1}\right), T$ is the temperature at $298 \mathrm{~K}$, and $B$ is the constant related to the heat of sorption $\left(\mathrm{Jmol}^{-1}\right)$. 

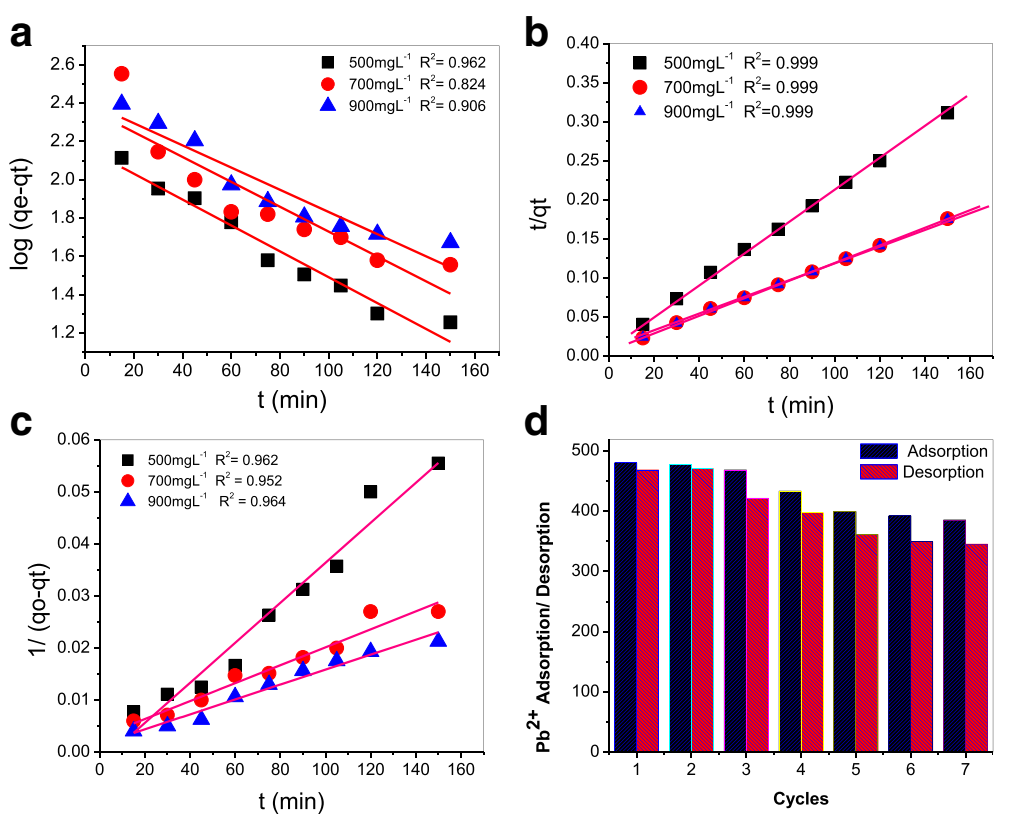

Fig. 7 Adsorption kinetics of heavy metals adsorption modeled at 500, 700, and $900 \mathrm{mgL}^{-1} \mathrm{~Pb}^{2+}$. a Lagergren first. b Pseudo-second order. c Second-order model. d Regeneration study of $\mathrm{Pb}^{2+}$ adsorption by templated silica xerogel (H900)

The equilibrium information best fitted to Langmuir model than Freundlich and Temkin models demonstrating surface homogeneity of the adsorbent and unilayer adsorption. Similar results have been observed in the adsorption of $\mathrm{Cd}^{2+}$ on Cassia Grandis seed gum-grafted poly(acrylamide)-silica hybrid (Singh et al. 2015), activated Eskom fly ash/chitosan composite (Pandey and Tiwari 2015), starch/silica nanocomposite (Singh et al. 2011a, 2011b) and adsorption of $\mathrm{Cr}^{6+}$ onto guar gum-grafted poly(methylacrylate) (Singh et al. 2009b).

From Langmuir isotherm, $Q_{\max }$ was calculated to be $2000 \mathrm{mgg}^{-1}$ demonstrating that the adsorbent had a high ability to remove $\mathrm{Pb}^{2+}$ ions (Fig. $6 \mathrm{a}-\mathrm{f}$ ). The estimations of Langmuir, Freundlich, and Temkin constants are displayed in Table 2. The Langmuir constant $b$ and Freundlich constant $K_{f}$ values expanded with expanding temperature from 15 to $30{ }^{\circ} \mathrm{C}$ inferring that the adsorption procedure was endothermic in nature and $\mathrm{Pb}^{2+}$ displayed the higher affinity for the adsorbent at the higher temperature than at the lower temperature. The intensity of adsorption $(n)$ increases from 2.59 to 3.01, with increase in temperature from 15 to $30{ }^{\circ} \mathrm{C} . R_{L}$ (the separation factor) is 0.324 and 0.425 at 15 to $30{ }^{\circ} \mathrm{C}$, respectively, for initial concentration of $100 \mathrm{mg} / \mathrm{L}$ indicating that the equilibrium sorption was favorable and the $R^{2}$ value is close to 1 proving that the sorption data fitted well to Langmuir isotherm model.

While Temkin plotted at two diverse temperature 15 and $30{ }^{\circ} \mathrm{C}$ as demonstrated in (Fig. 6e, f), the accompanying values were evaluated: $A_{T}=7.134 \mathrm{Lg}^{-1}$ and $B=395 \mathrm{Jmol}^{-1}$ and $A_{T}=3.9439 \mathrm{Lg}^{-1}$ and $B=347 \mathrm{Jmol}^{-1}$ at 15 and $30{ }^{\circ} \mathrm{C}$ separately, which is a sign of the heat of sorption showing a physical adsorption process.

\section{Sorption kinetics}

Adsorption kinetics, showing the solute uptake rate, is a standout amongst the most essential characters which speak to the adsorption efficiency of the templated silica xerogel (H900) and consequently decides their potential applications. The kinetic adsorption of $\mathrm{Pb}^{2+}$ onto adsorbent was demonstrated in Fig. 7. As an approximation, the removal of $\mathrm{Pb}^{2+}$ can be said to take place in two distinct steps: a relatively fast one followed by a slower one. The fundamental time to achieve this equilibrium is about $2 \mathrm{~h}$.

Kinetics of heavy metal adsorption was displayed by the first-order Lagergren mathematical statement, the pseudo-second-order equation, and the second-order rate equation (Ho and McKay 1998) indicated underneath as Eqs. (10, 11, and 12), separately (Fig. 7a-c).

$$
\begin{aligned}
& \log \left(q_{e}-q_{t}\right)=\log q_{e}-\frac{K_{l} t}{2.303} \\
& \frac{t}{q_{t}}=\frac{1}{K^{\prime} q_{e}^{2}}+\frac{t}{q_{e}} \\
& \frac{1}{\left(q_{e}-q_{t}\right)}=\frac{1}{q_{e}}+K_{2} t
\end{aligned}
$$

where $q_{e}\left(\mathrm{mg} \mathrm{g}^{-1}\right)$ and $q_{t}\left(\mathrm{mg} \mathrm{g}^{-1}\right)$ are the amount of metal ion adsorbed per unit mass of the adsorbent at 
Table 3 Thermodynamic parameters of the adsorption by templated silica xerogel ( $\mathrm{H} 900)$

\begin{tabular}{lccc}
\hline Temp $\left({ }^{\circ} \mathrm{K}\right)$ & $\Delta G^{0}\left(\mathrm{KJmol}^{-1}\right)$ & $\Delta H^{0}\left(\mathrm{KJmol}^{-1}\right)$ & $\Delta S^{0}\left(\mathrm{Jmol}^{-1}\right)$ \\
\hline 288.15 & -2.708 & 15.41 & 62.88 \\
303.15 & -3.323 & & 61.79 \\
\hline
\end{tabular}

equilibrium and at time $\mathrm{t}, K_{L}$ is the Lagergren rate constant of adsorption $\left(\mathrm{min}^{-1}\right) ; K^{\prime}$ is the pseudo-secondorder rate constant of adsorption $(\mathrm{g} / \mathrm{mg} / \mathrm{min})$ and $K_{2}$ the second-order rate constant $\left(\mathrm{gmg}^{-1} \mathrm{~min}^{-1}\right) ; q_{e}$ and $q_{t}$ are the amounts of metal ion sorbed $\left(\mathrm{mgg}^{-1}\right)$ at equilibrium and at time $t$, individually.

Linear plots of $\log \left(q_{e}-q_{t}\right)$ versus $t, t / q t$ versus $t$, and $1 /$ $\left(q_{e}-q_{t}\right)$ versus $t$ were indicated in Fig. 7a-c. The $K_{L}, K^{\prime}$, and $K_{2}$ values from the slopes and intercepts are $1.543 \times 10$ ${ }^{-2} / \mathrm{min}\left(R^{2}=0.962\right), 2.85 \times 10^{-4} \mathrm{gmg}^{-1} \mathrm{~min}^{-1}\left(R^{2}=0.999\right)$, and $3.8 \times 10^{-4} \mathrm{gmg}^{-1} \mathrm{~min}^{-1}\left(R^{2}=0.962\right)$, respectively, at $500 \mathrm{mgL}^{-1} \mathrm{~Pb}^{2+}$. The pseudo-second-order reaction rate model demonstrates satisfactorily the depicted kinetics of sorption of lead with high correlation coefficient $\left(R^{2}=\right.$ 0.999). Similar results have been observed in the adsorption of metal ions (Pandey and Ramontja 2016a) and dyes (Pandey and Ramontja 2016b) on different adsorbents.

Kinetics was performed at three diverse $\mathrm{Pb}^{2+}$ concentrations and the $R^{2}$ values and the rate constants for all the three models are recorded in Additional file 1: Table S4, showing that rate of adsorption was higher at $500 \mathrm{mgL}^{-1} \mathrm{~Pb}^{2+}$ concentration.

\section{Regeneration of saturated adsorbents}

For pragmatic application, the reusing and recovery of the adsorbent is essential. As a result of their insoluble nature of xerogel, the collection of $\mathrm{Pb}^{2+}$-adsorbed templated silica xerogel (H900) was simple and quick. We treated it with $0.01 \mathrm{~N} \mathrm{H}_{2} \mathrm{SO}_{4}$ solution which analyzed the concentration of $\mathrm{Pb}^{2+}$ ions desorbed to the solution by AAS. To make the sorbent economically competitive, the readied adsorbent ought to be reused for number of cycles. Ninety-six percent of the $\mathrm{Pb}^{2+}$ was uprooted in the first cycle. Adsorbed $\mathrm{Pb}^{2+}$ could be stripped by the presentation of protons that contended with metal ions for binding site. The utilized composite was treated with $0.01 \mathrm{~N} \mathrm{H}_{2} \mathrm{SO}_{4}$ which brought about to $93.6 \%$ stripping of $\mathrm{Pb}^{2+}$. The adsorption capacity was totally continued after the recovery of acid-treated sorbent. In the second cycle, the material could now remove $95.4 \% \mathrm{~Pb}^{2+}$ that could be desorbed up to $94 \%$. In the third cycle, $96.4 \%$ adsorption and $92.6 \%$ desorption were conceivable (Fig. $7 d$ ). The removal decreases ostensibly per cycle up to the seventh cycle recommending high proficiency of the adsorbent. In the last cycle, $77 \%$ adsorption was achievable.

It is fascinating to find that the structure of mesoporous templated silica xerogel (H900) could keep well amid the reuse tests with no change, even under persistent mechanical disturbance with mechanical agitation of $120 \mathrm{rpm}$ and mixing time of $21 \mathrm{~h}$. This affirms the stability of our adsorbent.

\section{Thermodynamic studies}

The estimations of thermodynamic parameters are significant for the functional use of adsorption procedure. Isotherm information identified with adsorption of $\mathrm{Pb}^{2+}$ onto the templated silica xerogel at $15{ }^{\circ} \mathrm{C}$ and at $30{ }^{\circ} \mathrm{C}$ were examined to acquire the estimations of thermodynamic parameters. Change in free energy $\left(\Delta G^{\circ}\right)$,

Table 4 Comparative list of the maximum sorption capacity $\left(Q_{\max }\right)$ for $\mathrm{Pb}^{2+}$ sorption of templated silica xerogel $(\mathrm{H} 900)$ by different adsorbent reported in the literature

\begin{tabular}{|c|c|c|c|}
\hline Adsorbent & $\begin{array}{l}\text { Conc. range } \\
\left(\mathrm{mgL}^{-1}\right)\end{array}$ & $\begin{array}{l}\mathrm{Pb}^{2+} \mathrm{Qmax} \\
\left(\mathrm{mgg}^{-1}\right)\end{array}$ & Reference \\
\hline $\begin{array}{l}\text { Sodium alginate supported tetrasodium thiacalix[4]arene tetrasulfonate } \\
\text { (TSTC[4]AS-S-SA) nanogel }\end{array}$ & 50 & 16.9 & (Lakouraj et al. 2014). \\
\hline Superparamagnetic nanocomposite of sodium alginate (Fe3O4@TSTC[4]AS-s-SA) & & 19.96 & \\
\hline Biodegradable cyclodextrin-based gel (CAM) & $25-150$ & 210.6 & (Huang et al. 2013). \\
\hline Phanerochaete chryosporium immobilized in alginate gel beads live & $30-600$ & 282 & (Arıca et al. 2003). \\
\hline Immobilized spore containing alginate beads (heat inactivated fungus) & & 355 & \\
\hline Palygorskite clay & $25-800$ & 104.28 & (Chen and Wang 2007) \\
\hline mwXG-g-PEA & $50-500$ & 142.86 & (Pandey and Mishra 2012) \\
\hline Magnetic chitosan hydrogel beads (m-CS/PVA/CCNFs) & $10-500$ & 171.0 & (Zhou et al. 2014). \\
\hline Chitosan entrapped in poly(acrylamide) & $25-2000$ & 173.88 & (Akkaya and Ulusoy 2008) \\
\hline $\begin{array}{l}\text { Chitosan-g-poly(acrylic acid)/attapulgite/sodium humate (CTS-g-PAA/APT/SH) } \\
\text { composite hydrogels }\end{array}$ & $300-4000$ & 862.07 & (Zhang and Wang 2010) \\
\hline Poly(acrylic acid) crosslinked by $N, N^{\prime}$-methylenebisacrylamide/montmorillonite & $50-500$ & 1666.7 & (Bulut et al. 2009) \\
\hline Templated silica xerogel (H900) & 500-2300 & 2000 & Present study \\
\hline
\end{tabular}


enthalpy $\left(\Delta H^{\circ}\right)$, and entropy $\left(\Delta S^{\circ}\right)$ for the adsorption procedure were ascertained utilizing the Eqs. (13, 14, and 15) (Gibbs 1928), and processed values are recorded in Table 3.

$$
\begin{aligned}
& \Delta G^{\circ}=-R T \ln b \\
& \frac{\ln b_{2}}{\ln b_{1}}=-\frac{\Delta H}{R}\left(\frac{1}{T_{2}}-\frac{1}{T_{1}}\right) \\
& \Delta G^{\circ}=\Delta H^{\circ}-T \Delta S^{\circ}
\end{aligned}
$$

where $\Delta G^{\circ}$ is the change in Gibbs free energy $\left(\mathrm{J} \mathrm{mol}^{-1}\right)$; $R$ is the universal gas constant $\left(8.314 \mathrm{~J} \mathrm{~K}^{-1} \mathrm{~mol}^{-1}\right) ; T, T_{1}$, and $T_{2}$ indicate as the temperatures (Kelvin); $\Delta H^{\circ}$ is the change in enthalpy $\left(\mathrm{J} \mathrm{mol}^{-1}\right) ; b_{1}$ and $b_{2}$ are the Langmuir constants at temperatures $T_{1}$ and $T_{2}$, respectively; and $\Delta S^{\circ}$ is the change in entropy $\left(\mathrm{J} \mathrm{mol}^{-1} \mathrm{~K}^{-1}\right)$

The thermodynamic parameters are recorded in Table 3 . Negative estimations of $\Delta G^{\circ}$ demonstrated that the adsorption procedure was favorable and spontaneous in nature. It might be noticed that with the increment in temperature from 15 to $30{ }^{\circ} \mathrm{C}$, the estimation of $\Delta G^{\circ}$ diminished from $-2.7 \mathrm{~kJ} \mathrm{~mol}^{-1}$ to $-3.3 \mathrm{~kJ} \mathrm{~mol}^{-1}$ Thus, adsorption of $\mathrm{Pb}^{2+}$ onto the composite was increased at higher temperature. The positive estimation of enthalpy change $\left(\Delta H^{\circ}\right)$ affirmed the endothermic way of the adsorption process. Positive estimations of $\Delta S^{\circ}$ proposed great affinity of the metal ion toward the adsorbent and expanded arbitrariness at the solid-solution interface amid the obsession of the metal ion on the active site of the adsorbent.

The $\mathrm{Pb}^{2+}$ adsorption capacities of some alternative sorbents reported in literature have been tabulated in Table 4 and compared with that of templated silica xerogel (H900). It demonstrates that adsorption capacity (Pandey and Mishra 2011b; Singh et al. 2010b; Singh et al. 2007c) is much higher than most sorbents reported in literature. Accordingly, because of its great adsorption capacity, simplicity of sample treatment, and additionally, accessibility, makes hybrid a promising savvy sorbent for $\mathrm{Pb}^{2+}$ removal from aqueous environment.

\section{Conclusions}

s-GG-g-PAN templating produces novel groups of intriguing porous solids displaying a regular mesostructure alongside high-specific surface areas, thermal and mechanical stability, exceptionally uniform pore distribution, and tunable pore size. $\mathrm{Pb}^{2+}$-binding capacity of the templated silica xerogel could be controlled by calcinations in air. The kinetics of the adsorption procedure was obtained by a pseudo-second-order model. The adsorption isotherm information fit better to the Langmuir adsorption isotherm, and the most extreme monolayer capacity of the adsorbent was observed to be $2000 \mathrm{mgg}^{-1}$ at $30^{\circ}$ C. The particular surface area and pore volume of the templated silica xerogel (H900) were observed to be $\left(240 \mathrm{~m}^{2} \mathrm{~g}^{-1}\right)$ and $\left(0.286 \mathrm{ccg}^{-1}\right)$, respectively. The $\% \mathrm{~Pb}^{2+}$ removal is observed to be $96 \%$ when H900 adsorbent was treated under ideal adsorption states of measurements $0.05 \mathrm{~g}$ dose, $500 \mathrm{mgL}^{-1} \mathrm{~Pb}^{2+}$ concentration, time $2 \mathrm{~h}$, and $\mathrm{pH} 5$ at $30{ }^{\circ} \mathrm{C}$. The $77 \%$ adsorption was achievable in the seventh cycle which shows the good recyclability of adsorbent.

\section{Additional file}

Additional file 1: Table S1. Lead binding by the templated silica xerogel ( $\mathrm{H} 80-\mathrm{H} 900)$ with respect to s-GG-g-PAN and non-templated silica xerogel (S900) using adsorbent dose $50 \mathrm{mg}, \mathrm{Pb}^{2+} 500 \mathrm{mgL}^{-1}$, temperature $\left(30^{\circ} \mathrm{C}\right)$, at 120 rpm, pH 5, 2 h, and in $50 \mathrm{~mL}$ solution. Table S2. Data of crystalline peaks in H900 sample along with $2 \theta$ (degree) and $d$ spacing. Table S3. Change of $\mathrm{pH}$ after adsorption (initial $\mathrm{pH}\left(\mathrm{pH}_{0}\right)$; equilibrium $\mathrm{pH}$ after adsorption $\left(\mathrm{pH}_{\mathrm{e}}\right)$ ). Table S4. Constant of kinetic models for $\mathrm{Pb}^{2+}$ adsorption on templated silica xerogel (H900). (DOC $58 \mathrm{~kb})$

\section{Acknowledgements}

The corresponding author is grateful to National Research foundation (NRF), South Africa (Grant No. 91399) for its liberal financial support. The authors also acknowledge University of Johannesburg (UJ) (South Africa) for the Lab and instrumentation facilities and UJ Online Library Services.

\section{Authors' contributions}

SP contributed to the experimental design, experimental work, analysis results, and writing. Both SP and JR contributed to the discussion and proofing and approved the final manuscript.

\section{Competing interests}

The authors declare that they have no competing interests.

Received: 12 May 2016 Accepted: 1 November 2016

Published online: 16 November 2016

\section{References}

Akkaya $\mathrm{R}$, Ulusoy $U$. Adsorptive features of chitosan entrapped in polyacrylamide hydrogel for $\mathrm{Pb}^{2+}, \mathrm{UO}_{2}{ }^{2+}$ and $\mathrm{Th}^{4+}$. J Hazard Mater. 2008;151:380-8.

Arıca MY, Arpa C, Ergene A, Bayramog $\ l u$ G, Gen O. Ca-alginate as a support for $\mathrm{Pb}(\mathrm{II})$ and $\mathrm{Zn}(\mathrm{II})$ biosorption with immobilized Phanerochaete chrysosporium. Carbohydr Polym. 2003;52:167-74.

Bulut Y, Akçay G, Elma D, Serhatli IE. Synthesis of clay-based superabsorbent composite and its sorption capability. J Hazard Mater. 2009;171:717-23.

Chen $\mathrm{H}$, Wang A. Kinetic and isothermal studies of lead ion adsorption onto palygorskite clay. J Colloid Interface Sci. 2007;307:309-16.

Eiden CA, Jewell CA, Wightman JP. Interaction of lead and chromium with chitin and chitosan. J Appl Polym Sci. 1980;25:1587-99.

Escudero R, Espinoza E, Tavera FJ. Precipitation of lead species in a $\mathrm{Pb}-\mathrm{H}_{2} \mathrm{O}$ system. Res J Recent Sci. 2013;2(9):1-4.

Feng Q, Xu J, Dong H, Li S, Wei Y. Synthesis of polystyrene-silica hybrid mesoporous materials via the nonsurfactant-templated sol-gel process. J Mater Chem. 2000;10:2490-4.

Feng N, Guo X, Liang S, Zhu Y, Liu J. Biosorption of heavy metals from aqueous solutions by chemically modified orange peel. J Hazard Mater. 2011;185:49-54.

Freundlich HMF. Uber die adsorption in losungen. Z Phys Chem. 1907;57(A):385-470.

Fu F, Wang Q. Removal of heavy metal ions from wastewaters: a review. J Environ Manag. 2011;92:407-18.

Ghorai S, Sinhamahpatra A, Sarkar A, Panda AB, Pal S. Novel biodegradable nanocomposite based on XG-g-PAM/SiO 2 : application of an efficient adsorbent for $\mathrm{Pb}^{2+}$ ions from aqueous solution. Bioresour Technol. 2012;119:181-90.

Gibbs JW. Collected works of J.W. Gibbs. New York: Longmans and Green; 1928. 
Goldstein AM, Alter EN, Seaman JK. In industrial gums; R.L. Whistler, J.N. BeMiller, Eds.; 1973 Academic Press: New York. 303-321.

Googerdchian F, Moheb A, Emadi R. Lead sorption properties of nanohydroxyapatitealginate composite adsorbents. Chem Eng J. 2012;200-202:471-9.

Han RP, Zou WH, Zhang ZP, Shi J, Yang JJ. Removal of copper (II) and lead (II) from aqueous solution by manganese oxide coated sand I. Characterization and kinetic study. J Hazard Mater. 2006;137:384-95.

Harrison RM, Laxen DPH. Lead pollution causes and control. New York: Chapman \& Hall; 1981. chap. 2.

Ho YS, McKay G. Sorption of dye from aqueous solution by peat. Chem Eng J. 1998;70:115.

Hua M, Zhang S, Pan B, Zhang W, Lv L, Zhang Q. Heavy metal removal from water/wastewater by nanosized metal oxides: a review. J Hazard Mater. 2012;211-212:317-31.

Huang Z, Wu Q, Liu S, Liu T, Zhang B. A novel biodegradable $\beta$-cyclodextrinbased hydrogel for the removal of heavy metal ions. Carbohydr Polym. 2013;97:496-501.

Kovac'evic' D, Pohlmeier A, O"zbas, G, Narres HD, Kallay MJN. The adsorption of lead species on goethite, Colloids Surf. A: Physicochem. Eng. Aspects 2000; 166 (1-3): 225-233.

Lakouraj MM, Mojerlou F, Zare EN. Nanogel and superparamagnetic nanocomposite based on sodium alginate for sorption of heavy metal ions. Carbohydr Polym. 2014;106:34-41.

Langmuir I. The constitution and fundamental properties of solids and liquids. Part I. Solids. J Am Chem Soc. 1916;38:2221-95.

Mishra SP, Singh VK, Tiwari D. Radiotracer technique in adsorption study: part XIV. Efficient removal of mercury from aqueous solutions by hydrous zirconium oxide. Appl Radiat Isot. 1996;47:15-21.

Olkhovyk O, Jaroniec M. Polymer-templated mesoporous organosilicas with two types of multifunctional organic groups. Ind Eng Chem Res. 2007;46(6):1745-51.

Oshima S, Perera JM, Northcott KA, Kokusen H, Stevens GW, Komatsu Y. Adsorption behavior of cadmium (II) and lead (II) on mesoporous silicate MCM-41. Sep Sci Technol. 2006;41:1635-43.

Pan B, Pan B, Zhang W, Lv L, Zhang Q, Zheng S. Development of polymeric and polymer-based hybrid adsorbents for pollutants removal from waters. Chem Eng J. 2009;151:19-29.

Pandey S. Highly sensitive and selective chemiresistor gas/vapor sensors based on polyaniline nanocomposite: a comprehensive review. J Sci. 2016. doi:10.1016/j.jsamd.2016.10.005

Pandey S, Mishra SB. Graft copolymerization of ethyl acrylate onto xanthan gum, using potassium peroxydisulphate as an initiator. Int J Biol Macromol. 2011a:49:527-35.

Pandey S, Mishra SB. Sol-gel derived organic-inorganic hybrid materials: synthesis, characterizations and applications. J Sol-Gel Sci Technol. 2011b; 59: 73-94.

Pandey S, Mishra SB. Organic-inorganic hybrid of chitosan/organoclay bionanocomposites for hexavalent chromium uptake. J Colloid Interface Sci. 2011C; 361 (2): 509-20.

Pandey S, Mishra SB. Microwave synthesized xanthan gum-g-poly(ethylacrylate): an efficient $\mathrm{Pb}^{2+}$ ion binder. Carbohydr Polym. 2012;90:370-9.

Pandey S, Mishra SB. Chromatographic resolution of racemic a-amino acids: chiral stationary phase derived from modified xanthan gum. Carbohydrate Polymer. 2013;92:2201-5.

Pandey S, Mishra SB. Catalytic reduction of p-nitrophenol by using platinum nanoparticles stabilised by guar gum. Carbohydrate Polymer. 2014;113:525-31.

Pandey S, Nanda KK. One-dimensional nanostructure based chemiresistive sensor, nanotechnology, Vol.10: Nanosensing 2013: 10:1-16. ISBN: 1-62699-010-7, Studium Press LLC, USA.

Pandey S, Nanda KK. Au nanocomposite based chemiresistive ammonia sensor for health monitoring. ACS Sensors. 2016;1:55-62.

Pandey S, Ramontja J. Natural bentonite clay and its composites for dye removal: current state and future potential. Am J Chem Appl. 2016a; 3 (2): 8-19.

Pandey S, Ramontja J. Turning to nanotechnology for water pollution control: applications of nanocomposites. Focus Sci. 2016b; 2 (2):1-10.

Pandey S, Ramontja J. Rapid, facile microwave-assisted synthesis of xanthan gum grafted polyaniline for chemical sensor. Int J Biol Macromol. 2016c; 89: 89-98.

Pandey S, Ramontja J. Sodium alginate stabilized silver nanoparticles-silica nanohybrid and their antibacterial Characteristics. Int J Biol Macromol. 2016d; 93:712-723. http://dx.doi.org/10.1016/j.jibiomac.2016.09.033

Pandey S, Tiwari S. Facile approach to synthesize chitosan based composite-characterization and cadmium (II) ion adsorption studies. Carbohydr Polym. 2015;134:646-56.
Pandey S, Goswami GK, Nanda KK. Green synthesis of biopolymer-silver nanoparticle nanocomposite: an optical sensor for ammonia detection. Int J Biol Macromol. 2012;51:583-9.

Pandey S, Goswami GK, Nanda KK. Green synthesis of polysaccharide/gold nanoparticle nanocomposite: an efficient ammonia sensor. Carbohydr Polym. 2013;94:229-34.

Pehlivan E, Arslan G. Removal of metal ions using lignite in aqueous solution: low cost biosorbents. Fuel Process Technol. 2007;88:99-106.

Pretorius PJ, Linder PW. The adsorption characteristics of $\delta$-manganese dioxide: a collection of diffuse double layer constants for the adsorption of $\mathrm{H}^{+}, \mathrm{Cu}^{2+}$, $\mathrm{Ni}^{2+}, \mathrm{Zn}^{2+}, \mathrm{Cd}^{2+}$ and $\mathrm{Pb}^{2+}$. Appl Geochem. 2001;16:1067-82.

Schneegurt MA, Jain JC, Menicucci JA, Brown SA, Kemner KM, Garmfalo DF, Quallick MR, Neal CR, Kulpa CF. Biomass byproduct DCHB for the remediation of wastewaters contaminated with toxic metals. Environ Sci Technol. 2001;35:3786-91.

Shchipunov YA. Sol-gel-derived biomaterials of silica and carrageenans. J Colloid Interface Sci. 2003;268:68-76.

Shchipunov YA, Tat'yana YK. Hybrid polysaccharide-silica nanocomposites prepared by the sol-gel technique. Langmuir. 2004;20:3882-7.

Shchipunov YA, Kojima A, Imae T. Polysaccharides as template for silicate generated by sol-gel processes. J Colloid Interface Sci. 2005;285:574-80.

Sheng PX, Ting Y, Chen JP, Hong L. Sorption of lead, copper, cadmium, zinc, and nickel by marine algal biomass: characterization of biosorptive capacity and investigation of mechanisms. J Colloid Interface Sci. 2004;275:131-41.

Siliva LCCd, Santos LBOd, Abate G, Cosentino IC, Fantini MCA, Masini JC, Matos JR. Adsorption of $\mathrm{Pb}^{2+}, \mathrm{Cu}^{2+}$ and $\mathrm{Cd}^{2+}$ in FDU-1 silica and FDU-1 silica modified with humic acid, Micropor. Mesopor. Mater. 2008; 110 (2-3): 250-259.

Singh V, Tiwari A, Pandey S, Singh SK. Microwave accelerated synthesis and characterization of potato starch-g-poly (acrylamide). Starch-Starke. 2006;58:536-43.

Singh V, Tiwari A, Pandey S, Singh SK, Sanghi R. Synthesis and characterization of novel saponified guar graft-polyacrylonitrile/silica nanocomposite materials. J Appl Polymer Sci. 2007a; 104:536-44.

Singh V, Tiwari A, Pandey S, Singh SK. Peroxydisulfate initiated synthesis of potato starch-graft- poly(acrylonitrile) under microwave irradiation. xPress Polymer Letters 2007b; 1: 51-58.

Singh V., Pandey S., Singh SK, Sanghi R. Synthesis of novel nanocomposites of silica and guar gum: efficient zinc ion binder. J Fudan University (Natural Science) 2007c; 46(5): 15

Singh V, Pandey S, Singh SK, Sanghi R. Sol-gel polycondensation of tetraethoxysilane in ethanol in presence of vinyl modified guar gum: synthesis of novel adsorbent nanocompositional materials. J Sol-Gel Sci Technol. 2008;47:58-7.

Singh V, Pandey S, Singh SK, Sanghi R. Removal of cadmium from aqueous solutions by adsorption by poly(acrylamide) modified guar gum-silica nanocomposites. Sep Purif Tech. 2009a; 67: 251-61.

Singh V, Kumari P, Pandey S, Narayan T. Removal of chromium (VI) using poly (methylacrylate) functionalized guar gum. Bio Resource Technol. 2009b; 100:1977-82.

Singh V, Kumari PL, Tiwari A, Pandey S. Alumina supported microwave synthesis of Cassia marginata seed gum-graft-poly(acrylamide). J Appl Polymer Sci. 2010a; 117: 3630-3638.

Singh V, Singh SK, Pandey S, Sanghi R (2010b) Adsorption behavior of potato starch-silica nanobiocomposite. Adv. Material Letter. 2010b; 1(1): 40-7.

Singh V, Singh SK, Pandey S, Kumar P. Sol-gel synthesis and characterization of adsorbent and photoluminescent nanocomposites of starch and silica. J Non-Cryst Solids. 2011a;357:194-201.

Singh V, Singh SK, Pandey S, Sanghi R. Synthesis and characterization of guar gum templated hybrid nano silica. Int J Biol Macromol. 2011b;49:233-40.

Singh V, Tiwari S, Pandey S, Preeti SR. Cassia Grandis seed gum-graftpoly(acrylamide)-silica hybrid: an excellent cadmium (II) adsorbent, Adv. Material Letters. 2015;6:19-26.

Tao C, Huang JG, Li JB. "Noodle-like" mesoporous silica templated by polyelectrolyte/surfactant complex. Chin Chem Lett. 2003;14:1175-8.

Tempkin Ml, Pyzhev V. Kinetics of ammonia synthesis on promoted iron catalyst. Acta Phys Chim. 1940;12:327-56.

Wan Y, Zhao D. On the controllable soft templating approach to mesoporous silicates. Chem Rev. 2007;107:2821-60.

Yang H-B, Chen Q, Song L, Lu J-Y, Li H-P. Double-pore structure and enzyme activity of $\mathrm{SiO}_{2}$ monolithic carrier. Chin J Inorg Chem. 2007;23:164-8. 
Yang H, Xu R, Xue X, Li F, Li G. Hybrid surfactant-templated mesoporous silica formed in ethanol and its application for heavy metal removal. J Hazard Mater. 2008;152:690-8.

Zhang J, Wang A. Adsorption of Pb(II) from aqueous solution by chitosan-gpoly(acrylic acid)/attapulgite/sodium humate composite hydrogels. J Chem Eng Data. 2010:55:2379-84.

Zhou Y, Fu S, Zhang L, Zhan H, Levit MV. Use of carboxylated cellulose nanofibrils-filled magnetic chitosan hydrogel beads as adsorbents for $\mathrm{Pb}(\mathrm{II}$. Carbohydr Polym. 2014;101:75-82.

\section{Submit your manuscript to a SpringerOpen ${ }^{\circ}$ journal and benefit from:}

- Convenient online submission

- Rigorous peer review

- Immediate publication on acceptance

- Open access: articles freely available online

- High visibility within the field

- Retaining the copyright to your article

Submit your next manuscript at $>$ springeropen.com 